\title{
Anesthetic Conduct in Cesarean Section in a Parturient with Unruptured Intracranial Aneurysm
}

Luciana de Souza Cota Carvalho, M.D., Walkiria Wingester Vilas Boas, TSA, M.D.

\section{INTRODUCTION}

An aneurysm represents a structural defect of the artery wall characterized by a reduction in the middle muscular layer of unknown etiology, but which probably results from a combination of genetic and hemodynamic factors, as well as alcohol and nicotine abuse ${ }^{1}$. Aneurysms usually develop on the bifurcation of blood vessels due to the turbulent blood flow in those areas, but some aneurysms are caused by infections or traumas ${ }^{2}$.

The incidence of aneurysms is approximately $2 \%$ in the general population'. Most aneurysms (80 to 90\%) are located in the anterior circulation (carotid), anterior and posterior communicating arteries and middle cerebral artery, while the remaining 10 to $20 \%$ affect the posterior circulation (vertebrobasilar $)^{2}$. The risk of rupture is approximately $1 \%$ a year, and the size of the aneurysm is the main risk factor for rupture; therefore, large aneurysms are associated with a greater risk of rupture. Other risk factors include location, age, gender, and smoking ${ }^{1}$. Aneurysms represent the main cause of spontaneous subarachnoid hemorrhage - approximately $75 \%$ of the cases ${ }^{2}$. The remaining episodes are idiopathic or caused by rare disorders, such as cerebral or vertebral arteriovenous malformation, arterial dissection, vasculitis, and tumor ${ }^{2}$.

The incidence of aneurysms in pregnancy is similar to that of the general population, but its rupture is more common during pregnancy (20 cases in 100,000 pregnancies $)^{3}$. This can be explained by pregnancy-related physiologic changes (increased blood volume and cardiac output, besides hormonal changes in the arterial wall) ${ }^{3}$. Subarachnoid hemorrhage has a somber prognosis during pregnancy, with a $35 \%$ risk of fatal maternal evolution and $25 \%$ fetal mortality ${ }^{3}$. In face of those considerations, we report the case of a pregnant woman with unruptured intracranial aneurysm scheduled for elective cesarean section. The anesthetic management for this condition is especially interesting. Firstly, because very few cases have been reported in the 
literature ${ }^{2}$. Secondly, because the choice of anesthesia and anesthetic management affects two patients (mother and fetus) and it has specific particularities due to maternal physiology and pregnancy-specific physiologic changes. Promoting safe maternal anesthesia and minimizing fetal compromise is the final objective.

\section{CASE REPORT}

This is a 31-year old multiparous (7 pregnancies, 3 deliveries, 3 miscarriages) women, 35-week pregnancy, with motor deficit on the left side of the body. A CT scan of the head showed a hyperdense lesion in the anterior circulation suggestive of a giant aneurysm of the anterior artery without signs of rupture. The patient had a history of hypertension and stroke without sequelae.

The patient evolved with spontaneous remission of symptoms and she was admitted to the hospital for observation. She did not develop intercurrences and had no other complaints, and delivery was scheduled for after the $37^{\text {th }}$ week of gestation. The patient was scheduled for a cesarean section to decrease maternal work and, after the risk of rupture was discussed with the medical team responsible for the case, simple epidural block was chosen. The patient was monitored with ECG, pulse oximeter, and non-invasive blood pressure. After careful antisepsis, the $\mathrm{L}_{3} / \mathrm{L}_{4}$ space was punctured with an 18G Tuohy needle using the loss of resistance technique. A bolus of $20 \mathrm{~mL}$ of $1 \%$ ropivacaine with $2 \mathrm{mg}$ of morphine was administered slowly and, after 10 minutes, the sensorial blockade reached $\mathrm{T}_{6}$ and surgery was initiated. The procedure evolved without intercurrences and the patient remained hemodynamically stable during the intraoperative period. Five minutes after the onset of the anesthetic blockade, a male fetus was removed; the fetus had an Apgar of 8, on the first minute, and 9, on the fifth minute. The patient had no intra- or postoperative complaints and neurologic changes were not observed.

\section{DISCUSSION}

Anesthetic management for cesarean section in patients with unruptured intracranial aneurysm involves the knowledge of neuroanesthesia and obstetric anesthesia. Regardless of the anesthetic technique, maintaining stable transmural pressure in the aneurysm to prevent rupture is the main objective.

Transmural aneurismal pressure (TP) is defined as the difference between the internal pressure of the aneurysm (mean arterial pressure - MAP) and external pressure (intracranial pressure - ICP), i.e., TP = MAP - ICP. Thus, an increase in MAP and/or reduction in ICP elevate transmural pressure, leading to aneurismal rupture. Based on this knowledge, some aspects of the anesthetic management of cesarean sections in a parturient with unruptured intracranial aneurysm under general anesthesia or subarachnoid or epidural block are discussed.

General anesthesia in obstetric patients has a higher incidence of complications than regional blocks. The relative mortality risk is $16.7^{5}$ when comparing general anesthesia and regional block and the majority of anesthesia-related maternal deaths are secondary to difficulties in airways management ${ }^{5}$.

The physiologic changes of pregnancy determine higher risk of pulmonary aspiration of gastric contents and difficult airways due to edema ${ }^{5}$. Thus, every elective intubation in parturients demands careful evaluation of the airways, prophylaxis of aspiration of gastric contents, and rapid sequence approach. If signs of anatomical difficulties for the management of the airways are identified and regional block is not an option, awake tracheal intubation should be considered $^{5}$. Rapid sequence intubation of possibly edematous airways or awake intubation can increase the risk of aneurismal rupture. Interventions like laryngoscopy and tracheal intubation cause considerable stimulation of the reflexes, and the resulting hemodynamic changes can cause dangerous increases in the transmural pressure of the aneurysm, increasing the risk of rupture ${ }^{2}$. Thus, induction and intubation are the most critical moments for intraoperative aneurismal rupture, with an incidence of 1 to $2 \%$, which is higher in patients with difficult airways ${ }^{2,6}$. Some strategies that can be used to decrease this hypertensive response to laryngoscopy and the risk of rupture include: administration of drugs that block or eliminate the hypertensive response, such as esmolol and lidocaine, and deep anesthetic plane (high doses of anesthetics, BIS monitoring) at the time of intubation $^{2,6}$. This objective can be achieved by using remifentanil, both as a bolus administration, immediately before potent stimuli, and continuous infusion, adjusting the dose for the respective degrees of stimulation ${ }^{2}$. However, the attempt to reduce the hypertensive response to laryngoscopy and tracheal intubation can increase the risk of fetal acute distress by reduction in maternal MAP and fetal heart rate 2,6 . To guarantee better control during those moments, intraoperative invasive blood pressure monitoring is indicated.

In face of what has been exposed, general anesthesia should not be discarded, but the anesthesiologist must remember those particularities and should try to reduce the response to laryngoscopy and, therefore, decrease the risk of aneurismal rupture during anesthetic induction without compromising the fetus, if possible.

Other techniques that could be used in those cases include subarachnoid block or epidural block. As a rule, in obstetrics, neuroaxis block is considered the technique of choice in most cases since it is safer for both mother and fetus ${ }^{7}$. However, this technique is not devoid of risks. And in patients with unruptured aneurysms, cases of aneurismal rupture after lumbar puncture have been reported in the literature ${ }^{8-13}$. Puncture of the dura mater can reduce intracranial pressure and trigger the rupture of an aneurysm. However, other causes of rupture, such as postoperative hypertension or spontaneous 
rupture, cannot be ruled out. In most cases it is not possible to confirm whether puncture of the dura mater is the cause or just a coincidence. Considering the high prevalence of underdiagnosed unruptured aneurysms (approximately $2 \%$ of the general population) and the large number of neuroaxis blocks performed every year, one would expect a high incidence of post-spinal block subarachnoid hemorrhage. However, a review of the literature revealed only 11 reports of post-spinal block subarachnoid hemorrhage ${ }^{8-18}$. Thus, it is thought that subarachnoid hemorrhage after spinal block is, most likely, a rare situation and, therefore, this technique would be relatively safe in this case, especially when one considers the technical resources currently available (small gauge needles with low risk of acute cerebral spinal fluid hypotension), the lack of elevation of MAP in subarachnoid block, and inherent risks of general anesthesia in pregnant women. Thus, subarachnoid block would be the first choice of the anesthesia team; however, the neurosurgical team responsible for the case reported here did not agree with this technique, but they agreed with the epidural block.

Epidural block is, indeed, an extremely safe technique in the absence of accidental puncture of the dura mater, which could be catastrophic due to the possibility of sudden and severe fall in ICP. The technique was carefully performed, without accidental puncture of the dura mater, which allowed for an uneventful procedure.

We conclude that the literature has very few reports on this subject. Evidence-based recommendations for obstetric anesthesia in patients with unruptured intracranial aneurysm do not exist. Experimental or clinical data indicating or contraindicating general anesthesia or regional blocks in this context are lacking. Therefore, the decision on which technique should be used is individual, weighing the risks and benefits of each procedure and the experience of the anesthesiologist.

\section{REFERÊNCIAS - REFERENCES}

01. Rinkel G - Natural history, epidemiology and screening of unruptured intracranial aneurysms. Rev Neurol (Paris), 2008; 164:781-786.

02. Priebe $\mathrm{H}$ - Aneurysmal subarachnoid haemorrhage and the anaesthetist. Br J Anaesth, 2007;99:102-118.

03. Wang L, Paech MJ - Neuroanesthesia for the pregnant woman. Anesth Analg, 2008;107:193-200.

04. Duggan T, Simpson A - An unusual intracranial aneurysm presenting in pregnancy. Int J Obstet Anesth, 2008;17:194-195.

05. Goldszmidt E - Principles and practices of obstetric airway management. Anesthesiol Clin, 2008;26:109-125.

06. Guy J, McGrath B, Borel CO et al. - Perioperative management of aneurysmal subarachnoid hemorrhage: Part 1. Operative management. Anesth Analg, 1995;81:1060-1072.

07. Stamer UM, Wulf H - Complications of obstetric anaesthesia. Curr
Opin Anaesthesiol, 2001;14:317-322.

08. Sreedhar R, Gadhinglajkar SV - Lumbar puncture can precipitate bleed from unsuspected intracranial aneurysm. Indian J Anaesth, 2002;46:386-390.

09. Böttiger BW, Diezel G - Acute intracranial subarachnoid hemorrhage following repeated spinal anesthesia. Anaesthesist, 1992; 41:152-157.

10. Wells JB, Sampson IH - Subarachnoid hemorrhage presenting as post-dural puncture headache: a case report. Mt Sinai J Med, 2002;69:109-110.

11. Eggert SM, Eggers KA - Subarachnoid haemorrhage following spinal anaesthesia in an obstetric patient. $\mathrm{Br} \mathrm{J}$ Anaesth, 2001;86: $442-444$

12. Coursange F, Aubert M, Gosset $S$ et al. - Rupture d'un anevrysme intracranien dans les suites d'une rachianesthesie. Ann Fr Anesth Reanim, 1987;6:113-114.

13. von Knobelsdorff G, Paris A - Intracerebral hemorrhage after cesarean section under spinal anesthesia. Coincidence or causality? Anaesthesist, 2004;53:41-44.

14. Mantia A - Clinical report of the occurrence of an intracerebral hemorrhage following post-lumbar puncture headache. Anesthesiology, 1981;55:684-685.

15. Benzon $\mathrm{H}$ - Intracerebral hemorrhage after dural puncture and epidural blood patch: nonpostural and noncontinuous headache. Anesthesiology, 1984;60:258-259.

16. Laubach S, Reber A - Subarachnoid haemorrhage after spinal anaesthesia for caesarean section. Anaesthesist, 2004;53: 723-726.

17. Saitoh $\mathrm{K}$, Hirabayashi $\mathrm{Y}$, Mitsuhata $\mathrm{H}$ et al. - Subarachnoid hemorrhage unexpectedly found on spinal anesthesia. Anesthesiology, 1994;81:1312.

18. Sharma K - Intracerebral hemorrhage after spinal anesthesia. J Neurosurg Anesthesiol, 2002;14:234-237.

\section{RESUMEN}

Carvalho LSC, Vilas Boas WW - Conducta Anestésica en Cesárea en Embarazada con Aneurisma Cerebral Íntegro.

JUSTIFICATIVA Y OBJETIVOS: EI manejo anestésico para la cesárea programada en embarazada con aneurisma cerebral íntegro es particularmente interesante, porque presenta diversas particularidades relacionadas con las alteraciones fisiológicas del embarazo y por añadidura, con los riesgos de ruptura del aneurisma durante el procedimiento anestésico. La literatura es parca en ese asunto, siendo muy importante la divulgación de los casos.

RELATO DEL CASO: Embarazada de término, 31 años, con aneurisma cerebral no roto y sometida a la cesárea programada bajo anestesia epidural simple. El procedimiento evolucionó sin intercurrencias para la madre y el hijo.

CONCLUSIONES: No existen recomendaciones basadas en evidencias, para la anestesia obstétrica en pacientes portadoras de aneurisma cerebral no roto. No hay datos experimentales o clínicos que confirmen o que refuten la anestesia general o regional en ese contexto. Por lo tanto, la decisión de cuál técnica utilizar, debe ser usada con bases individuales, mensurado los riesgos y los beneficios de cada procedimiento y la experiencia del profesional que la llevará a cabo. 